\title{
Encounters with Reggio Emilia: Relationships, Equality, and Citizenship in Our Early Learning Setting
}

\author{
Valerie Trew and Kimberly Squires
}

\begin{abstract}
Valerie Trew is the director at the University of Guelph Child Care and Learning Centre in Guelph, Ontario, Canada. She also teaches in the bachelor of applied science program at the University of Guelph-Humber with a focus on policy, administration, and leadership. Valerie has spent almost 20 years working in children's services through postsecondary education, regional government, inclusion and early intervention, and early leaning and child care. Email: trewv@uoguelph.ca
\end{abstract}

Kimberly Squires is the pedagogical leader at the University of Guelph Child Care and Learning Centre. She also teaches in the bachelor of applied science program at the University of Guelph with a focus on early learning pedagogy and administration. She has worked in both child care and school-based early learning and care settings during her more than 10 years in the field. Email: ksquires@uoguelph.ca

In this paper, we discuss what it has meant for us to be inspired by Reggio Emilia's pedagogical approach within our licensed child care and laboratory school context in Ontario, Canada. We focus on three aspects of the Reggio Emilia approach - relationships, equality, and citizenship - which we believe are interpretable across many different contexts. We speak about the importance of these aspects and offer narratives of how we have been inspired to reconceptualize our own relationships, use of language, and concept of citizenship to construct new aspirations in the early learning field.

Key words: Reggio Emilia; early childhood; relationships; language use; citizenship
Reggio Emilia's pedagogical approach has inspired the practices of early learning professionals worldwide. But upon travelling to Reggio Emilia and learning directly from the pedagogistas in the northern Italian city, it quickly became apparent to us that context is everything. The post-World War II social and political conditions, along with the northern Italian culture that gave rise to this revolutionary early learning pedagogy, were instrumental in the evolution of an approach that incorporates the values of democracy and recognizes children as full, participating citizens.

Given the importance of the context of the Reggio Emilia approach, we recognize that it is essential to consider our own context while exploring this inspiration. It is important to acknowledge our perspective as educators in a licensed child care centre in Ontario, Canada. We are located on a university campus and function as the laboratory school for an interdisciplinary department focused on human health and development. With four toddler classrooms, four preschool classrooms, and a school-age outdoor learning program, we are a large centre. Our programs have been exploring ideas inspired by Reggio Emilia for several years, and in March 2018, we attended the Ontario Reggio Association (ORA) Canadian study week to Reggio Emilia to further our research.

In this article, we investigate the impact that researching the Reggio Emilia approach has made within our specific context and offer narratives illustrating this effect. After closely examining our experience during the study week, we identified key concepts from the Reggio Emilia approach that have inspired us, and we share them in the following review. We believe that these concepts can be explored within any context that aspires to achieve an early learning program that is responsive to and honours its time, place, and participants. Focusing on relationships as the foundation for a pedagogical approach fosters a strong image of the child, which can be expressed and supported through language use and by encouraging engaged citizenship, making it adaptable to any context while remaining true to the principles of Reggio Emilia. 


\section{The foundation of relationships}

The Reggio Emilia approach uses relationships as the foundation of learning. Relationships within the Reggio Emilia system resemble a web connecting children, educators, parents, community members, local government, environments, and materials (Fraser, 2012; Infant-Toddler Centres and Preschools Istituzione of the Municipality of Reggio Emilia, 2010). Central to these relationships is an image of the child as competent, strong, powerful, and, most importantly, connected-to adults, children, environments, materials, and communities (McNally \& Slutsky, 2017).

As we explored the schools, neighbourhoods, and municipality of Reggio Emilia, we noticed many elements that we felt would pose challenges within our North American context. The nature of our regulations and cultural norms around community, such as fears about "stranger danger," are limitations we identified. Rather than being discouraged by these limitations, we were inspired to find opportunities for equally rich experiences that are possible within our context. Fortunately, regardless of context, relationships are vital to child development and learning. Using relationships as a foundation for a Reggio-inspired approach has allowed us to incorporate some of the principles of Reggio Emilia in a manner that meets educators where they are at in their journey and builds on existing strengths within our own context.

\section{Relationships in the Ontario context}

In thinking about our context in Ontario, we considered the Ontario Ministry of Education's guiding document How Does Learning Happen? Ontario's Pedagogy for the Early Years and its focus on relationships, which is immediately apparent given the document's subtitle, "A resource about learning through relationships for those who work with young children and their families" (Ontario Ministry of Education, 2014). In describing one of its four foundational conditions, belonging, the document mentions the importance of forming and valuing relationships with others, while relationships with the surrounding world are briefly mentioned. The concept of children being in relation with materials is only suggested, and the document does not reflect the same depth of the concept that we observed in Reggio Emilia.

\section{A foundation of relationships within the CCLC}

In thinking about relationships within our context at the University of Guelph Child Care and Learning Centre (CCLC), we considered our on-site community garden project. We embarked on this project at the beginning of 2018 because of our beliefs regarding environmental stewardship and our desire to strengthen relationships between our on-site kitchen and classrooms and the children's relationships with nature and food. We also took this opportunity to enrich relationships between our centre and its families and, with that, our centre and academia. Many of our families work in academic disciplines across campus, and we hoped that some parents would be able to contribute relevant academic knowledge to the project, such as information about plant biology and agriculture. Through this constellation of relationships, we hoped to offer opportunities for our classrooms and on-site kitchen to collaborate and for the children to develop a clearer understanding of where food comes from and the process of growing and caring for it. We also hoped to offer a more specialized opportunity to which some families could contribute. We envisioned using the garden produce in our on-site kitchen, as well as having it available for our families to take home.

Our first step was to secure funding to cover the community garden's startup costs. Keeping in mind our relationship-focused goals, we started a fundraising project involving the families and classrooms. We put together a cookbook of recipes from our kitchen with proceeds used to fund the garden (see Figure 1). Since we were reducing recipes meant to feed more than 100 children down to five or six portions, we put out a call to our families 
to act as recipe "test kitchens." We asked participating families to share their experiences with us by providing feedback on the details and clarity of the recipe and the experience of making the dish with their children. We were overwhelmed with the response and engagement of our children, families, and educators and received a wide variety of stories, photographs, and drawings to incorporate in the cookbook. Our classrooms engaged in the creation of the cookbook by studying some of the recipe ingredients to create illustrations and stories.

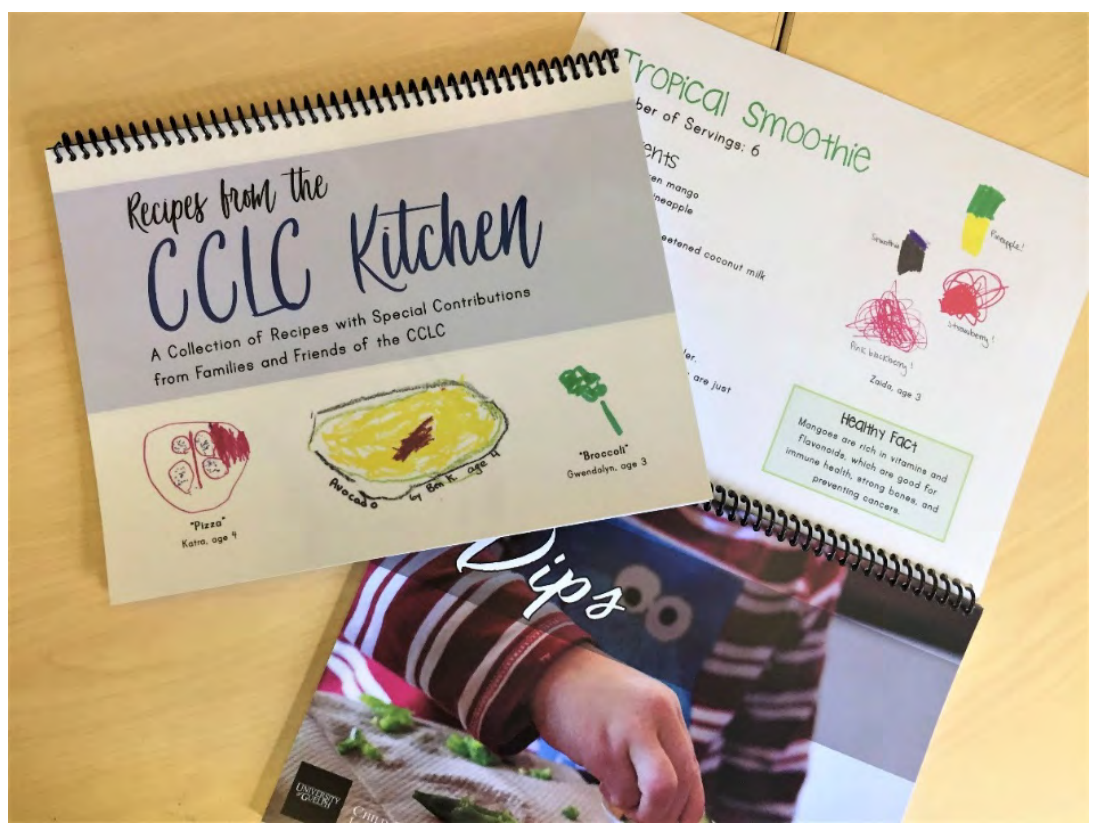

Figure 1. The final printed version of the cookbook created with contributions from the children, families, and educators.

Once spring came, we formed a garden committee of educators and family volunteers that provided leadership and knowledge for the implementation and upkeep of the garden. The garden committee planned many aspects, including layout, sourcing of compost, and sourcing of plants. We recognized that we would need a fence around the garden to protect the plants, but were unable to have this built by a department on-campus within our timeline or budget. Instead, a small group of educators and families gathered to design and build the fence through many evening and weekend volunteer hours. Once the fence was finished, we planned several "planting mornings" where children, educators, and family members helped to plant the garden (see Figure 2). 

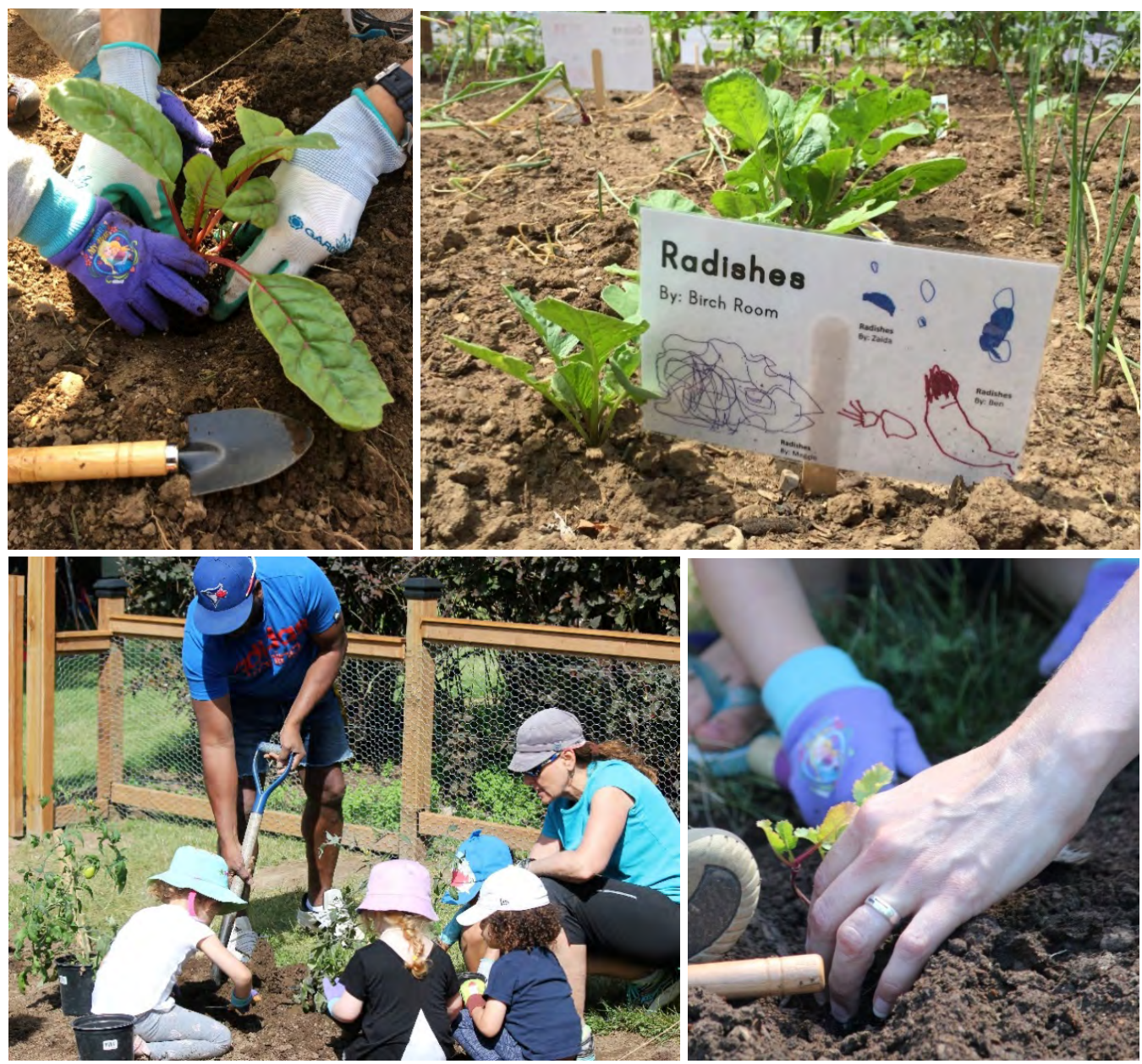

Figure 2. Images from planting our community garden with the children, educators, and families.

As the garden has grown, our children, families, and educators have worked together to care for it by labelling, watering, weeding, and harvesting (see Figure 3). Daily rituals of watering and observing the garden have been created and a co-ownership has developed. Rather than the garden being merely a small pet project of a few people, many of our children, educators, and families have developed a relationship with "their garden" —and with each other through the garden.
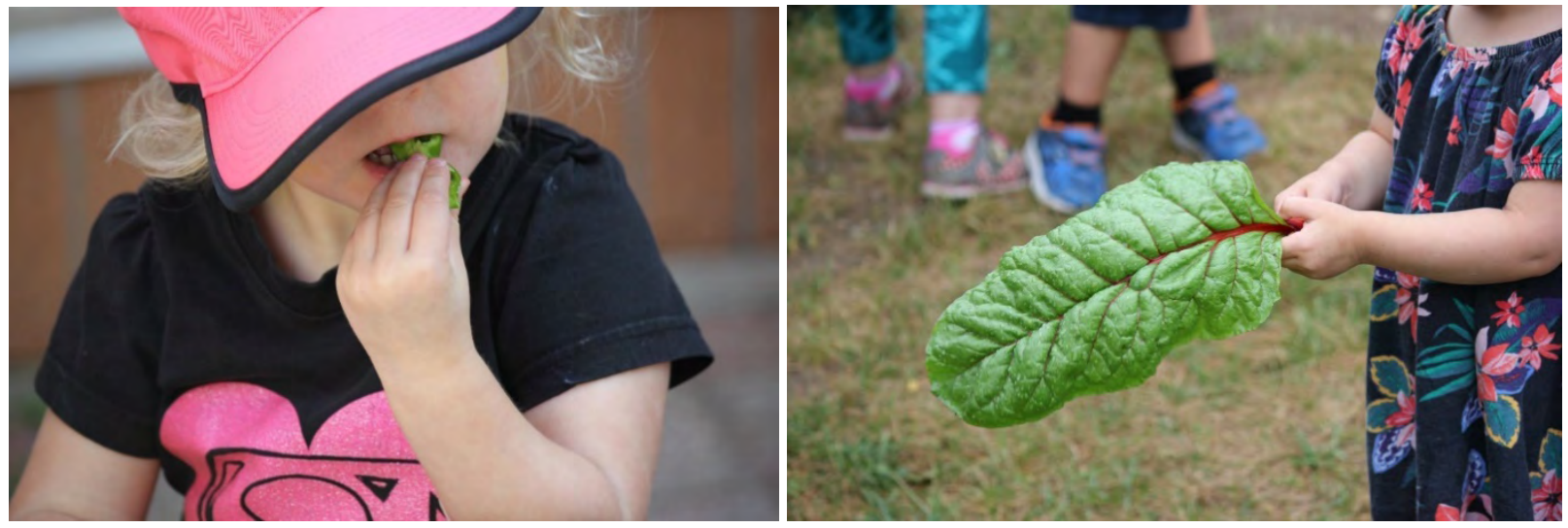

Figure 3. The children harvesting and eating vegetables grown in the community garden. 
Our garden's location at the front of our building by a main road on campus has also helped in creating relationships. The various people and vehicles that pass by each day have watched the progress of our garden project and word has travelled across campus. Although this was not something we initially anticipated, relationships with other departments on campus have strengthened through this project. Excited by our garden, the campus sustainability team installed a system of composters that enable reuse of vegetable scraps from our kitchen to create enough compost to prepare our garden's soil for next season (see Figure 4).

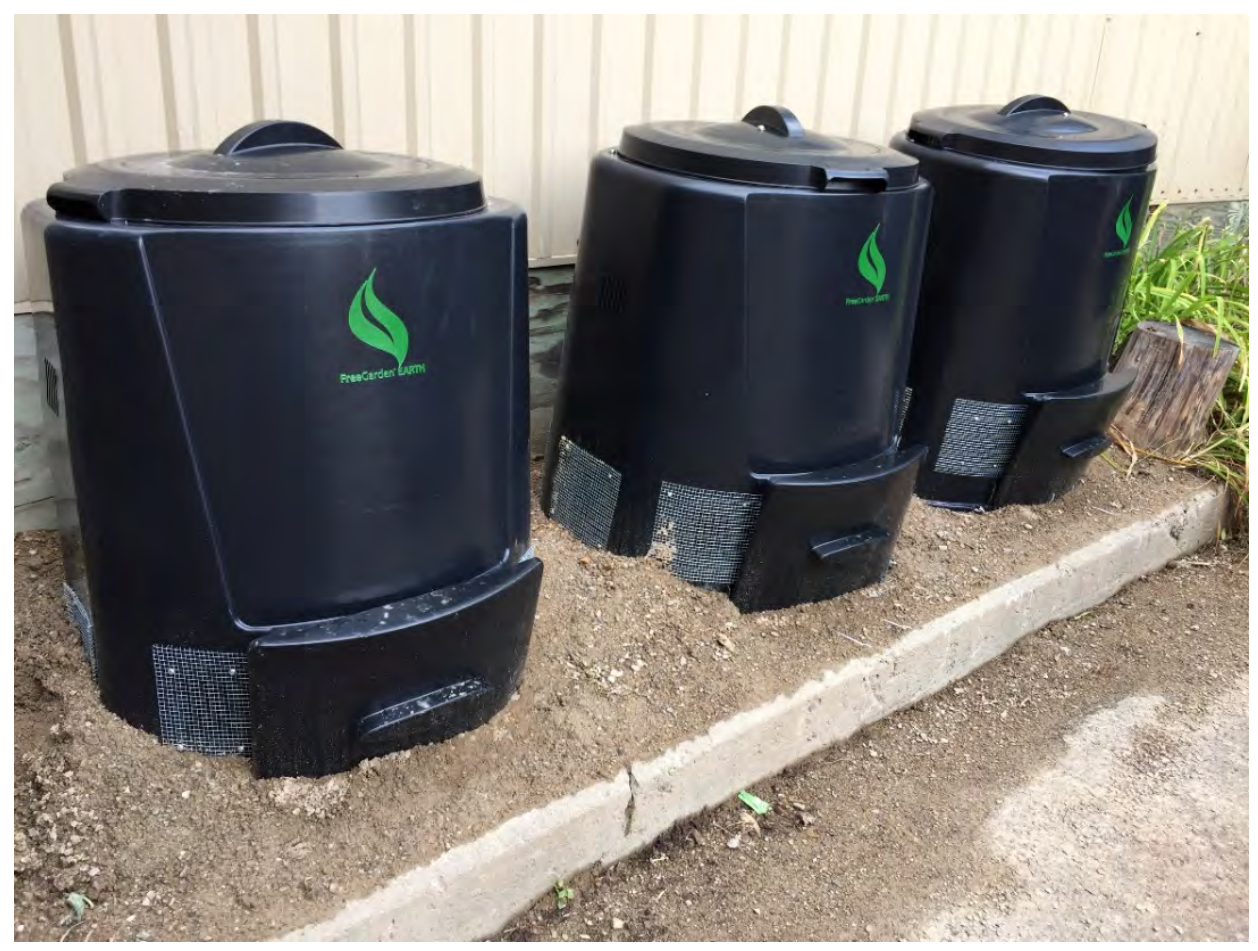

Figure 4. The composting system installed by our on-campus sustainability team.

Though this project initially started out small, its reach has grown as the network of relationships has expanded. It has been a tool for creating and strengthening relationships and has helped us focus on the importance of these relationships within our centre. The garden has given us invaluable perspective on future projects and how we might plan, structure, and execute them in a responsive way to make relationships not only a priority but an essential outcome of any endeavours.

\section{Encountering a "language of equality"}

Something we noticed in our observations at the schools of Reggio Emilia and through the videos presented during the study week was what we refer to as a "language of equality." The educators in Reggio Emilia used language that was rich and sophisticated in their discussions with children. Their conversations with children could have just as easily been conversations with colleagues. They discussed matters, invited dialogue with and between children, and arrived at decisions and outcomes that would not have been possible through "top down" interactions common in many early learning environments. We were so struck by this language of equality that we documented specific phrases we heard that conveyed respect, equality, partnership, and sometimes even deferral. These phrases included "Do you agree with what s/he said?"; "I'm proposing ..."; "In my opinion ..."; "It is interesting what s/he has discovered"; "Shall we ..."; "I don't agree ..." 


\section{"Language of equality" at the CCLC}

In 2018, five of our educators explored their use of a language of equality in a three-week action research project to gain a better understanding of the impact it could have. The project started with a meeting between the pedagogical leader and each of the participating educators to share, in depth, our observations of the use of language that we had observed in Reggio Emilia. We watched a video of a learning experience in Reggio Emilia and discussed specific phrases and approaches we observed the teacher using and the impact we felt these had on the quality of interactions. We related these to our existing understanding of language use and discussed our current language practices, which we realized had a power imbalance between educator and child. We decided on a structure for the action research project that included providing coverage several times a week for educators to write reflections to be shared with their colleagues engaging in the research. To conclude the research, we met once more with each of the educators to debrief and to offer the opportunity to share their reflections about their use of a language of equality.

The educators' reflections varied throughout the three-week period as they focused on different aspects of the research. As they challenged preconceived notions, we observed similar learnings develop related to their role and impact in their interactions with children.

After several reflective sessions, we prompted the educators to share their conceptualizations of a language of equality. Having spent time thinking more intentionally about their language use, the educators described the furthering of partnerships in their interactions with children. This revelation was contrary to their previous view, which tended to be more focused on the influence they were going to have on interactions, often by giving directions or information. In one of her final reflections, an educator wrote:

What does language of equality mean to me? Originally, I would have answered this by saying that the children deserve our respect and understanding of their capabilities. I would still say this is true, but I also think it means a partnership with the children-learning together and from each other.

Through their reflections and experiences, the educators developed an understanding of what it could mean to engage in dialogue with the children, becoming more aware of the impact of their responses on these relationships. If we are to create more equality within our interactions with children, their perspectives and ideas should be taken seriously and given careful consideration, rather than simply being agreed with (Swadener, Peters, \& Gaches, 2013). A process of exchange should occur, just as it would in a dialogue between two adults (Chan, 2010). In their reflections, the educators expressed comfort while agreeing with the children and commented on the positive impact they observed these exchanges having on the children's relationships with them, with each other, and with their environment. As the research progressed, we encouraged the educators to challenge themselves and observe the impact that disagreeing with a child could have. In a discussion about what animals they might see while visiting the on-campus arboretum, an educator tested this concept by telling a child she did not agree with her statement that they would see a lion. Reflecting on this situation, the educator wrote, "I found it awkward to disagree with the child at first, feeling like we try to acknowledge all answers, but the child was receptive." When she later verbally shared her narrative of this situation with us, she expressed that, though it had been uncomfortable initially, disagreeing with the child showed a higher level of respect for the children by ensuring that they had a more realistic and accurate worldview.

A final aspect of language of equality that became apparent through the research was the topics of conversation. The educators expressed comfort with topics more commonly seen as something that children understand (e.g., conversations about their families, daily routines, and learning experiences). At one point during her research, an 
educator broached the topic of her substantial hearing loss with the children for the first time:

I reflected on this conversation later because it's the first time in my almost 20 years working with children that I have told them about my loss of hearing. I wondered why-was it because I didn't think they'd understand? Or did I feel it wasn't important to them?

The conversation was started by the children pointing out that the educator had not responded to one child's greeting. The educator was accustomed to brushing this off in previous instances by responding, "Oh, sorry! I didn't hear you." However, during this particular interaction she decided to share the reason because she wanted to give the children a more accurate answer. It was interesting that the educator had never before shared this information with the children and brought an important realization that it is not enough to simply consider the way we speak with children but also what we speak about. These initial five educators found this project to be so impactful that we decided to offer the experience to the rest of our educators.

\section{Citizenship as a method of community engagement}

Just as relationships form the foundation of the Reggio Emilia approach, creating community is its purpose (McNally \& Slutsky, 2017). Children are invested in as a civic commitment (McNally \& Slutsky, 2017), and viewed as participating citizens. Italian culture values coming together, and spaces are designed and built with gathering in mind. The purpose of creating community seems a natural extension of the foundation of relationships.

The concept of citizenship varies depending on the research reviewed, but one definition that is commonly accepted is "a status bestowed on those who are full members of a community. All who possess the status are equal with respect [to] rights and duties" (Marshall, 1950, as cited in Lister, 2007, p. 2). From this definition, we can see that the key elements of citizenship are essentially membership, rights, and equality. Membership is often the most recognized aspect of citizenship within a community, though the understanding of what it means to be a member is context specific (Lister, 2007). To be members of a community, children must be welcomed to participate and contribute in a way that allows them to be seen and heard. Children's citizenship is dependent on the definition, not only of citizenship, but of childhood (Lister, 2007). Therefore, the early learning profession in North America has a responsibility to advocate for a redefinition of childhood that is based on competence, participation, and rights.

\section{Engaged citizenship at the CCLC}

When thinking about citizenship within our context, it was essential to consider our position within the University of Guelph. Specifically, we needed to consider our visibility within, and contribution to, this community. As an undergraduate teaching institute, we maintain a close partnership with the Department of Family Relations and Applied Nutrition. Each year, children in our programs develop close relationships with undergraduate students who complete practica and work placements within our centre. Many families within our centre are also students or employees of the university. Our classrooms frequently visit different areas of campus, including the arboretum, University Centre, library, art gallery, and agricultural animal facilities. During these excursions, the children receive enthusiastic responses from the community; however, we are often viewed as visitors to these spaces and not necessarily community members. To us, our membership within the university community has become more apparent as our contributions have developed. With increasing concern about student wellness, we wondered what we could offer in support of this important cause that might fulfill our responsibility as members of this community. From this concern, two initiatives were started: our "Cards of Kindness" campaign and "The Heart of Art: An Art Show Created by Preschoolers.” 
Through relationships with the undergraduate students, the children have learned about the students' educational experiences and have developed some understanding of exams. They have learned that it can be a particularly busy and stressful time for the students and have often offered small tokens of kindness. Through our "Cards of Kindness" campaign, we aimed to extend these experiences by partnering with the University of Guelph Academic Services. Cards were created with space on one side for a child to draw a picture and with a list of academic and personal student resources on the other side. At the end of each semester, children in our programs have worked together to decorate and distribute these cards across campus, much to the surprise and gratitude of the undergraduate students (see Figure 5). Through the experience of distributing the cards, the children have been able to observe the impact that their actions have had on the students' lives. To our surprise, the support we have received for this campaign has grown across our city, and the campaign has been featured in several local news reports (see Figure 6).

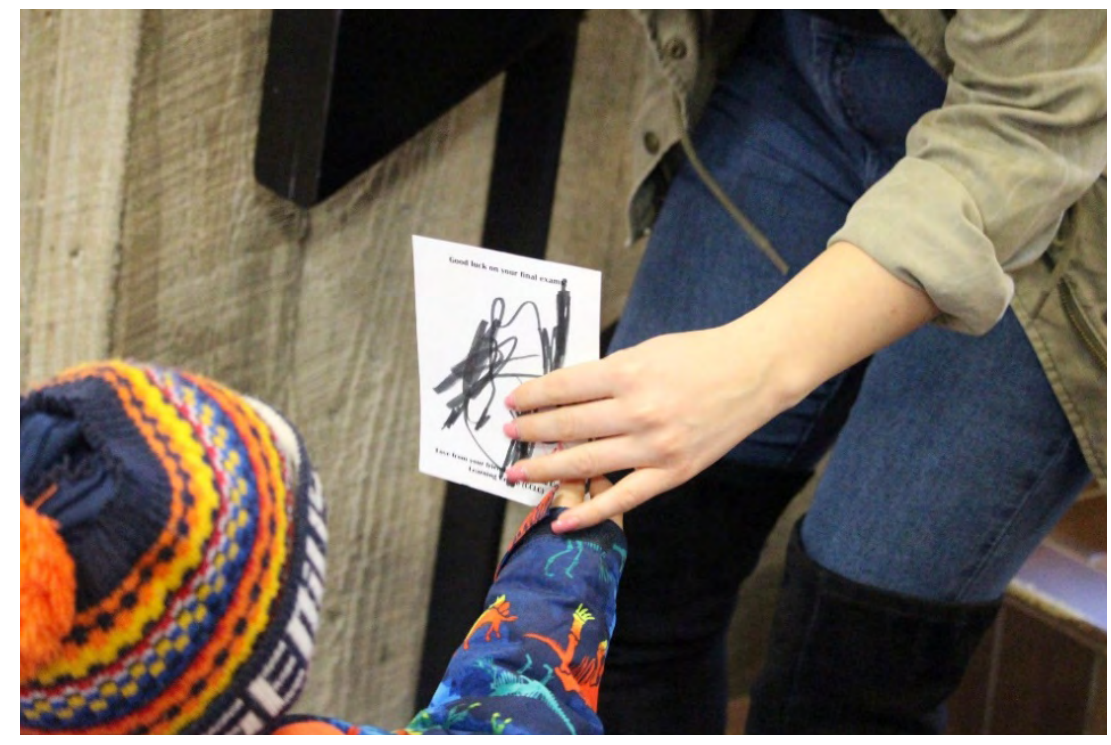

Figure 5. A child giving out a "card of kindness" during the exam period.

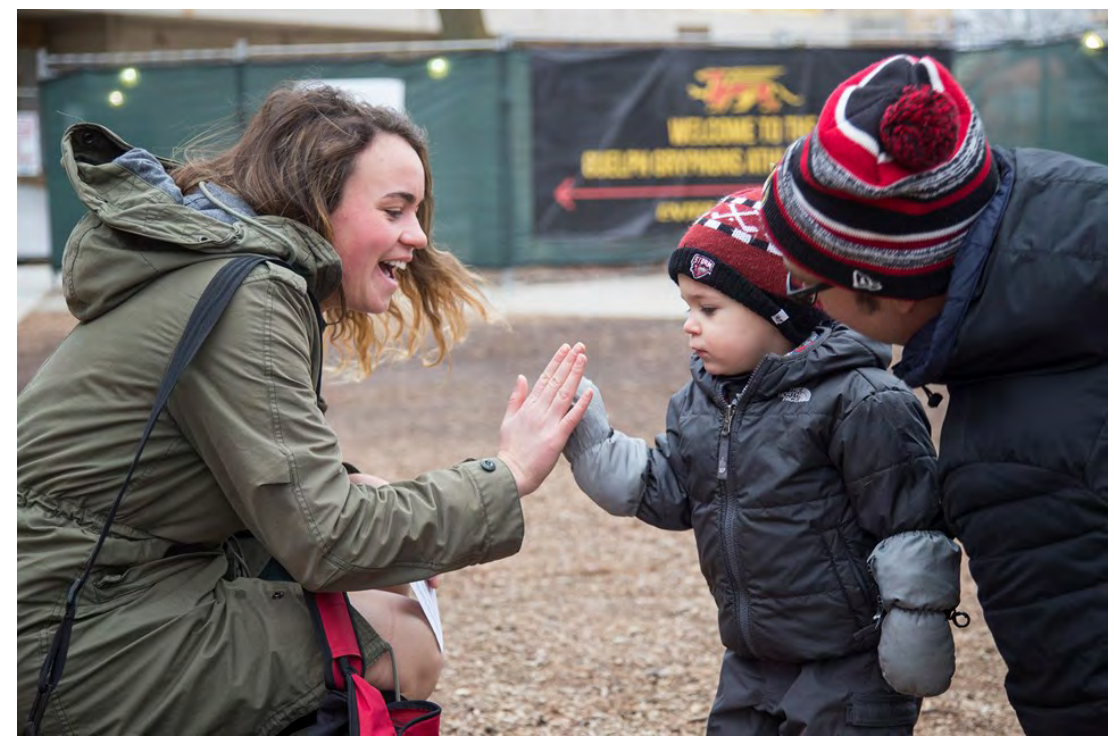

Figure 6. Image from a GuelphToday article about our Cards of Kindness campaign (Armstrong, 2017). 
It is a tradition within our centre to celebrate when the children "graduate" from our program. The classrooms have celebrated this in different ways over the years, including our senior preschool classroom creating an annual art show down the main hallway of our centre. The art was displayed for several days and made a lasting impression on the children, families, educators, and visitors. While considering our contributions to our university community, we recognized that this annual art show had the potential to have a greater impact if we were able to make it more visible. We contacted the University Centre management and arranged to display a larger art show in a main study lounge for one week of the exam period (see Figure 7). All four of our preschool classrooms decided to work together on this project, each creating several exhibits showcasing the theories and reflections they had been researching in their classrooms. The exhibit received a welcomed response from the students and employees using and passing through the study area. Over 50 comment cards were left about the impact that the displays had, particularly related to supporting student wellness during the exam period (see Figure 7). As part of this project, we also hosted an evening reception in the lounge at the end of the week. Our educators, preschool families, and some community members attended the reception to celebrate the children's time in our programs and their contributions as members of the University of Guelph community.
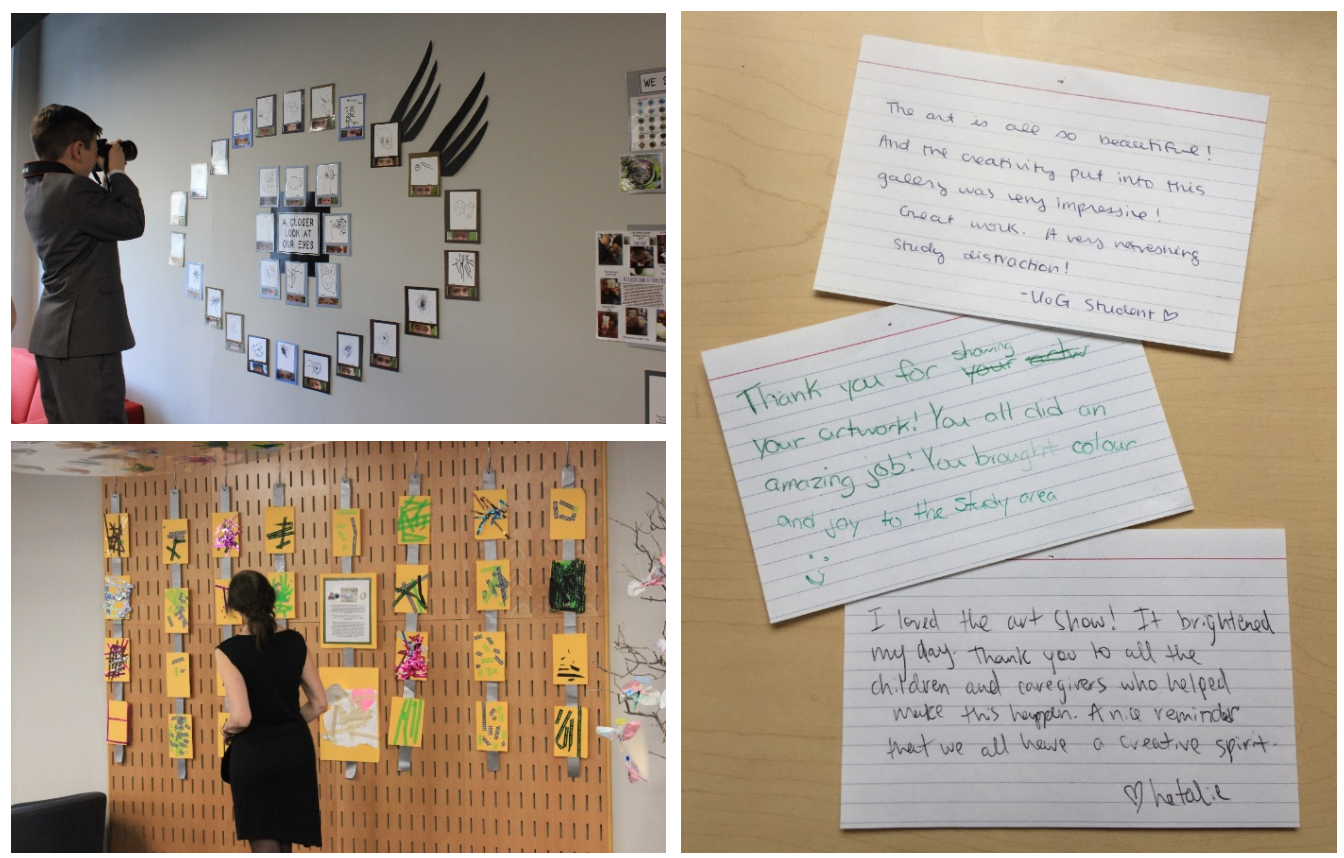

Figure 7. Images from the art show displayed in the University Centre.

\section{The impact of our encounters with Reggio Emilia}

Through our experiences with our community garden, language research, cards of kindness, and preschool art show, we encountered the key concepts from the Reggio Emilia approach that most inspire us-relationships, equality, and citizenship. Educators reflecting on the experiences describe children making meaningful contributions to their community; realizing their ability to make a positive impact on another person; forging relationships through shared experiences; and how competent and capable the children felt as they harvested vegetables, displayed their art, approached students to offer a card, or engaged in deep, reciprocal conversation with their teacher.

But perhaps most importantly, our educators have been transformed by the experiences. One educator describes how she was affected by the garden-feeling content, connected, and peaceful after time in the garden with 
the children. Another educator felt a deep sense of pride and gratitude for the opportunity to "give back to the community" through creating and maintaining the garden. In reflecting on the cards of kindness and community garden, one educator described working in partnership with the children, feeling her agenda fall away to welcome the children's natural investigation and direction. Educators described a sense of collaboration and common purpose while preparing for the preschool art show, with the objective of making the abilities and talents of their children visible to the community. For the educators, views of the child were affirmed or expanded by witnessing their capacity for caring, compassion, kindness, and brilliance.

These key concepts from the Reggio Emilia approach that most inspire us, deepened through experiences within our early learning setting, continue to shape our pedagogical approach. While embarking on these community activities in recent years, we have remained open to the unknown-the opportunities for these encounters to be shaped by the time, place, and participants. The interdependence created by these experiences, solidified through the reflections of our educators and community members, affirmed our view of our organization as a living organism (Filippini, 2001). While inspired by Reggio Emilia, we are reminded that there is no "recipe for Reggio." You cannot define Reggio because you cannot define what happens when children, educators, environments and materials come together (Filippini, 2001). We can, however, continually define and redefine ourselves and our programs based on a foundation of relationships, equality, and citizenship.

\section{Acknowledgements}

We would like to thank all of the educators at the University of Guelph Child Care and Learning Centre for giving us the inspiration to share their stories. We would like to specifically thank Tanya Doran, Sabah Hoosein, Angela Marshall, Leigh-Anne Stafford, and Chris Veaudry for their permission to publish parts of their reflective research. 


\section{References}

Armstrong, K. (2017, November 29). With “cards of kindness," preschoolers wish U of G students good luck on exams. GuelphToday. Retrieved from https://www.guelphtoday.com/local-news/with-cards-of-kindness-preschoolers-wishing-u-of-g-students-good-luck-onexams-8-photos-778388

Chan, K. H. (2010). Rethinking children's participation in curriculum making: A rhizomatic movement. In V. Pacini-Ketchabaw (Ed.), Flows, rhythms, \& intensities of early childhood education curriculum (pp. 39-53). New York, NY: Peter Lang.

Filippini, T. (2001). On the nature of organization. In C. Giudici, C. Rinaldi, C., \& M. Krechevsky (Eds.), Making learning visible: Children as individual and group learners (pp. 52-57). Reggio Emilia, Italy: Reggio Children.

Fraser, S. (2012). Authentic childhood: Experiencing Reggio Emilia in the classroom (3rd ed.). Toronto, ON: Nelson Education.

Infant-Toddler Centres and Preschools Istituzione of the Municipality of Reggio Emilia. (2010). Indications: Preschools and infant-toddler centres of the municipality of Reggio Emilia. Reggio Emilia, Italy: Reggio Children.

Lister, R. (2007). Unpacking children's citizenship. In A. Invernizzi \& J. Williams (Eds.), Children and citizenship (ch. 1) London, UK: SAGE. http://dx.doi.org/10.4135/9781446214756.n1

McNally, S. A., \& Slutsky, R. (2017). Key elements of the Reggio Emilia approach and how they are interconnected to create the highly regarded system of early childhood education. Early Childhood Development and Care, 187(12), 1925-1937. https://doi.org/10. 1080/03004430.2016.1197920

Ontario Ministry of Education. (2014). How does learning happen? Ontario's pedagogy for the early years: A resource about learning through relationships for those who work with young children and their families. Retrieved from http://www.edu.gov.on.ca/childcare/ HowLearningHappens.pdf

Swadener, B. B., Peters, L., \& Gaches, S. (2013). Taking children's rights and participation seriously: Cross-national perspectives and possibilities. In V. Pacini-Ketchabaw \& L. Prochner (Eds.), Resituating Canadian early childhood education (pp. 189-210). New York, NY: Peter Lang. 